\title{
Aspectos econômicos e operacionais das viagens da frota pesqueira de Manaus, Amazônia Central.
}

\author{
Renato Soares CARDOSO ${ }^{1}$; Vandick da Silva BATISTA² ${ }^{2}$ Charles Henry Faria JÚNIOR ${ }^{3}$; Wilson Ramos MARTINS ${ }^{4}$
}

\begin{abstract}
RESUMO
A pesca na Amazônia representa uma importante atividade social, econômica e cultural, com desembarque de pescado estimado em 25 mil toneladas por ano, somente no terminal de desembarque de Manaus, porém com poucas avaliações socioeconômicas que são fundamentais para o manejo da atividade. O presente trabalho visou avaliar aspectos funcionais das operações de pesca sob o ponto de vista econômico. As informações foram coletadas por intermédio de questionário estruturado junto aos proprietários das embarcações e, ou encarregados das expedições de pesca, entre outubro de 1999 e junho de 2000. Foram amostradas 92 embarcações, para destacar os aspectos referentes aos custos efetuados quando das expedições de pesca. Embarcações pequenas apresentaram custo operacional médio por expedição de $45,2 \%$ da renda bruta da venda do pescado, embarcações médias e grandes apresentaram valores de $42,0 \%$ e $47,8 \%$ dos custos respectivamente. Os combustíveis se destacaram como o componente principal destes custos.
\end{abstract}

\section{PALAVRAS-CHAVE}

pesca, economia da pesca, manejo pesqueiro.

\section{Economical and operational aspects of the fishing trips of Manaus fleet, Central Amazonia.}

\begin{abstract}
Fishery in the Amazon represents an important social, economic and cultural activity with yearly fish landings around 25 thousand tons in the fishing harbour of Manaus alone, with little socioeconomic evaluations that are fundamental for its management. The present paper sought to evaluate functional aspects of fishing operations from the economic point of view. Information was collected from 92 boats, between October of 1999 and June of 2000, through questionnaires given to boat owners or general managers of fishing expeditions. Small fishing boats presented mean operational cost of $45.2 \%$ of the gross income of fish sales. Medium and larger boats presented values of $42.0 \%$ and $47.8 \%$ costs, respectively, where fuel was the main expenditure.
\end{abstract}

\section{KEY WORDS}

fisheries, economy, management fisheries.

\section{INTRODUÇÃO}

A pesca na Amazônia Central representa uma importante atividade socioeconômica, que abastece o principal centro consumidor da região, a cidade de Manaus, Amazonas, com cerca de 25 mil toneladas de pescado por ano desembarcadas através do posto de desembarque pesqueiro local (Merona \& Bittencourt, 1988; Batista, 1998). Entretanto, apesar desta importância, esse setor da economia regional recebe pouca atenção dos segmentos políticos e sociais encarregados de executar o planejamento do desenvolvimento socioeconômico da região.

A atividade na região está concentrada na categoria de espécies silvestres que dependem de sua reprodução natural em rios e lagos da região (FAO, 1997). É uma pesca de pequena escala com caráter artesanal (Berkes et al., 2001), a qual pode ser identificada pelo desembarque disperso nos centros consumidores da região, em horários

\footnotetext{
${ }^{1}$ Engenheiro de Pesca, Mestrando em Biologia de Água Doce e Pesca Interior, Av. André Araújo, 2936 - Petrópolis. CEP. 69011-970. E-mail: renato4@inpa.gov.br; rsconpisci@yahoo.com.br

${ }^{2}$ Prof. Dr. Departamento de Ciências Pesqueiras, Universidade Federal do Amazonas. Av. Gal. Rodrigo O. J. Ramos, 3000 , Manaus, Amazonas. CEP 69077000. E-mail: tchoni@uol.com.br

${ }^{3}$ Engenheiro de Pesca, Mestre em Biologia de Água Doce e Pesca Interior, charleshanry@yahoo.com.br

${ }^{4}$ Graduando em Engenharia de Pesca - Universidade Federal do Amazonas.
} 


\section{ACTA \\ AMAZONICA}

ASPECTOS ECONÔMICOS E OPERACIONAIS DAS VIAGENS

DA FROTA PESQUEIRA DE MANAUS, AMAZÔNIA CENTRAL diversificados, parcialmente sem pesagem ou controle efetivo da representatividade do que entra nas feiras e mercados em relação ao total desembarcado. Isto tem colaborado para gerar uma série de lacunas existentes nas informações que norteiam a evolução dessa atividade, dificultando a obtenção de dados históricos que permitam subsidiar o manejo da atividade e dos recursos, o que ocorre com freqüência em tais pescarias em águas interiores (FAO, 1999). Além disso, cabe ressaltar a escassez de pesquisas com enfoque socioeconômico na região, gerando apenas abordagens bio-ecológicas que não viabilizam avaliar instrumentos efetivos para o manejo da atividade.

$\mathrm{Na}$ pesca comercial do Estado do Amazonas, a composição dos custos das expedições de pesca é diferenciada por categoria de embarcação, devido às suas diferentes características físicas (Batista, 1998), aos locais de captura e a duração da expedição de pesca (Parente, 1996). Os custos de produção no caso da pesca, são aqueles considerados essenciais para a realização das expedições de pesca, como combustíveis, gelo, rancho e adiantamento(s). Os custos de comercialização são aqueles decorrentes das taxas pagas pelo desembarque e a comissão do despachante no momento da comercialização da produção (Falabella, 1994; Parente, 1996). Estes custos são ressarcidos após a venda do pescado e o lucro eventual é dividido em parcelas denominadas de cotas-parte, entre o armador e os participantes da pesca, de acordo com a função exercida (Parente, 1996).

Neste trabalho foram obtidas e analisadas algumas informações necessárias para conhecer e compreender aspectos fundamentais do funcionamento da pesca, principalmente sob o ponto de vista econômico e dos agentes envolvidos, no intuito de contribuir com a administração do setor pesqueiro na tomada de decisões mais realistas. Procurou-se assim, determinar informaçõeschave à avaliação dos empreendimentos pesqueiros efetuados ao nível dos armadores de pesca, além de descrever aspectos relevantes do perfil socioeconômico da pesca profissional que abastece a cidade de Manaus, determinando os principais itens componentes da estrutura de custos do processo de exploração pesqueira.

\section{MATERIAIS E MÉTODOS}

A coleta dos dados ocorreu entre outubro de 1999 e junho de 2000. O levantamento foi efetuado no Posto de Desembarque Pesqueiro de Manaus, aplicando um questionário estruturado diretamente com os proprietários das embarcações de pesca ou com os encarregados das embarcações. Foram aplicados questionários para 92 diferentes embarcações de pesca. Obtiveram-se dados sobre as dimensões físicas das embarcações, capacidade de armazenamento, pesqueiros freqüentados, número de tripulantes, composição e custos de aquisição dos apetrechos de pesca, custos da expedição de pesca, custos de comercialização do pescado, critérios de divisão das despesas e receitas, custos envolvidos quando da manutenção dos apetrechos de pesca e da embarcação nos últimos três meses, gasto anual de manutenção da embarcação de pesca e número de expedições nos últimos três meses.

Foram calculadas as médias referentes aos custos por expedição de pesca, por categoria das embarcações, bem como a freqüência de desembarque das embarcações por município de origem. Foi efetuada ainda, uma regressão envolvendo os dados de comprimento da embarcação e custo operacional médio das expedições de pesca para adequação de um modelo matemático que explique a relação entre os dois itens.

Para classificar as embarcações adotou-se o critério: embarcações pequenas, com comprimento de até 10 metros; embarcações médias, com medidas maiores que 10 e menores que 20 metros; embarcações grandes, maiores que 20 metros. Essa classificação foi utilizada para verificar se os custos operacionais médios das embarcações de pesca variam entre as classes e, em que magnitude isso ocorre.

A análise da economicidade da pesca realizou-se por intermédio da diferença entre os custos necessários para a partida da expedição de pesca (somatório dos gastos) e o faturamento bruto obtido na expedição ou na média das últimas expedições de pesca após a comercialização do pescado e descontada a parte do despachante.

Nesta análise foram considerados como custos operacionais os itens: combustíveis (diesel, gasolina, óleo lubrificante), gelo, rancho, adiantamento e taxa cobrada pela Colônia dos Pescadores.

As análises foram efetuadas em Real, sendo que para efeito comparativo é informado que um dólar americano no período oscilou em torno de $\mathrm{R} \$ 1,50$.

\section{RESULTADOS}

Da análise dos dados, verificou-se que 39\% das embarcações pesqueiras são provenientes de Manaus (Figura 1), 37\% de Manacapuru, e o restante de outros municípios do interior do Estado do Amazonas.

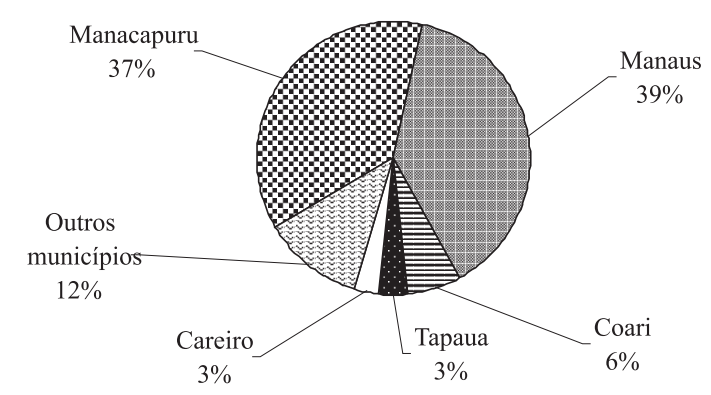

Figura 1 - Local de origem das embarcações de pesca que abastecem Manaus. 


\section{ACTA AMAZONICA}

Os principais pesqueiros explorados se localizam no rio Purus (Figura 2), seguido dos pesqueiros nos rios Solimões, Coari e Madeira.

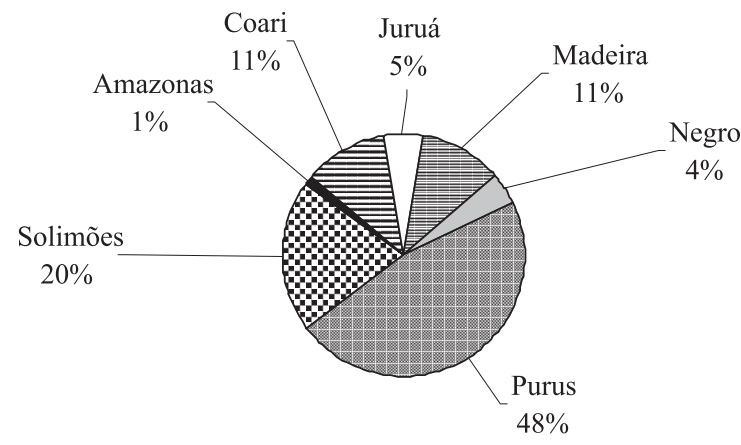

Figura 2 - Freqüência de citação de rios principais utilizados pela frota pesqueira que abastece Manaus.

\section{Características da frota amostrada}

Das embarcações amostradas, 9\% foram de pequeno porte, $69 \%$ de médio porte e $22 \%$ de grande porte, com comprimentos variando entre 9,0 e 25,9 metros.

Quanto ao número de tripulantes embarcados, foi detectado um aumento diretamente relacionado com o porte das embarcações, sendo catalogados em média 5 para embarcações pequenas, 8 para médias e 14 para as de grande porte.

Quanto a dependência da atividade pesqueira por parte dos donos de embarcação, em 56\% das embarcaçóes amostradas, os armadores vivem exclusivamente da pesca, $26 \%$ têm outra atividade econômica além da pesca e o restante não souberam informar (Figura 3). A constatação de que no contexto geral, a maioria dos donos das embarcações vivem exclusivamente da pesca é que apenas $26 \%$ dos proprietários de embarcações grandes, afirmaram possuir outra atividade para geração de renda.

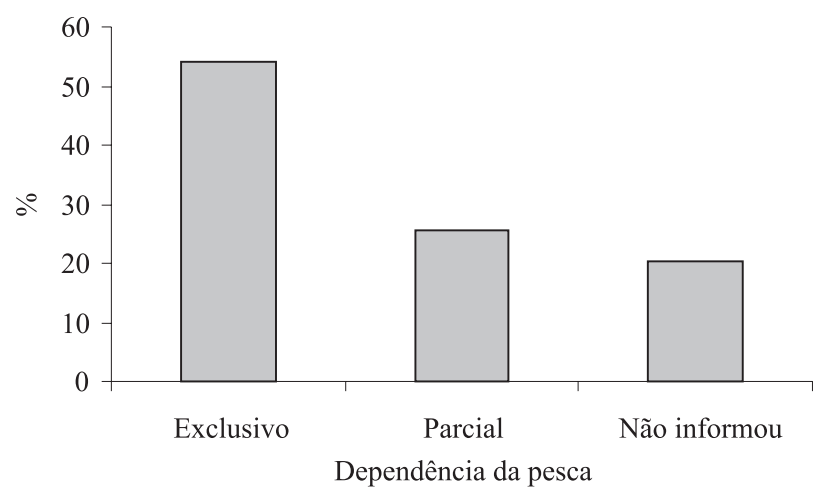

Figura 3 - Freqüência relativa de dependência da atividade pesqueira por parte dos armadores de pesca.

\section{Motores e apetrechos utilizados pelas embarcações}

$\mathrm{Na}$ composição dos apetrechos de pesca das embarcações pequenas amostradas predominou a malhadeira "tramalha" e nas embarcações médias e grandes predominou a redinha (Figura 4).

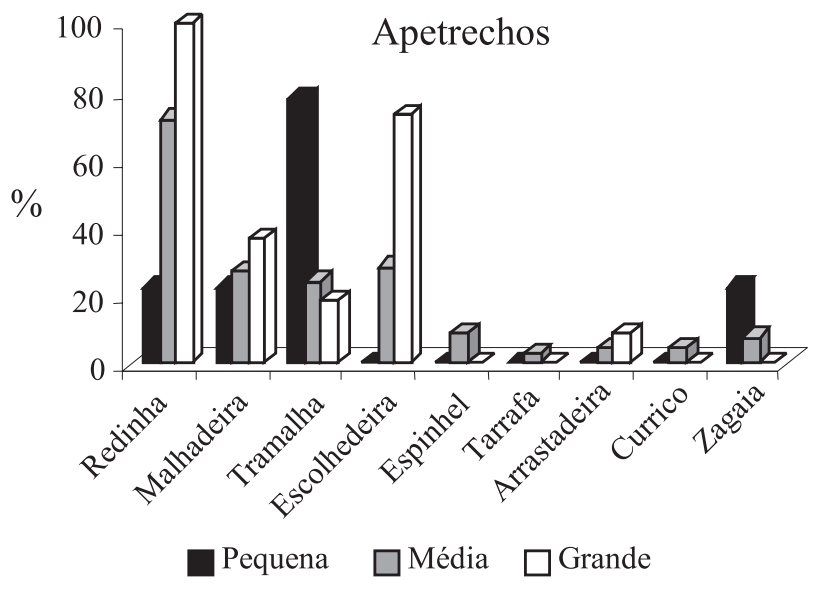

Figura 4 - Freqüência de ocorrência dos apetrechos nas embarcações de pesca por categoria de tamanho.

Os tipos de apetrechos de pesca foram mais numerosos na categoria das embarcações de médio porte (10 tipos), comparativamente ao registrado para as demais categorias (3 e 6, respectivamente para pequenos e grandes).

Avaliando o capital investido pelos armadores para aquisição dos apetrechos e canoas de apoio, as embarcações pequenas tiveram investimentos médios de $\mathrm{R} \$ 1.576,11$ para a compra dos mesmos, as embarcações de médio porte tiveram investimentos médios de $\mathrm{R} \$ 10.570,55 \mathrm{e}$ as embarcações grandes de $\mathrm{R} \$ 42.296,27$.

No pertinente às máquinas de propulsão das embarcações, foi registrada a dominância dos motores YANMAR em 86\% dos casos amostrados, seguido dos motores MWM (7\%) dos motores SCANIA (5\%), sendo apenas $2 \%$ composto por máquinas de outras marcas.

\section{Agentes financiadores das embarcações de pesca}

A identificação dos agentes financiadores dos insumos necessários para uma expedição de pesca, no caso os apetrechos de pesca, canoas auxiliares, combustíveis, gelo, rancho, manutenção dos apetrechos e barco, são apresentados na Figura 5, onde observamos que o armador se destaca como figura principal no financiamento da infraestrutura e da manutenção da mesma. Porém, com exceção dos adiantamentos (encargo do armador), os itens de maior dispêndio para o custeio das expedições (combustíveis, gelo e rancho) são freqüentemente financiados por seus 
frigoríficos e seus prepostos, por despachantes ou pelos fornecedores (comércio em geral e balsas fornecedoras de combustíveis, os pontões, para grandes embarcações).
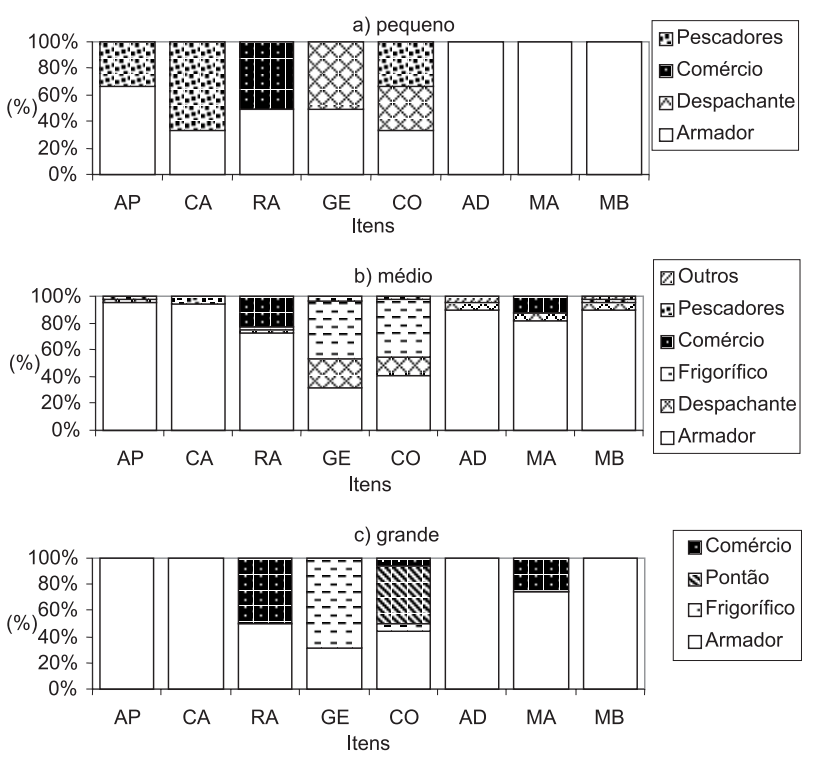

Figura 5 - Agentes financiadores das expedições de pesca de embarcações pequenas (a); médias (b); grandes (c). São indicados nas figuras: AP-apetrechos; CA-canoas; RA-rancho; GE-gelo; COcombustíveis; AD-adiantamento; MA-manutenção dos apetrechos; MB-manutenção do barco.

\section{Análise dos custos com as expedições de pesca}

Para embarcações grandes e médias, o custo operacional médio foi de $\mathrm{R} \$ 9.300,00$ e $\mathrm{R} \$ 2.300,00$ respectivamente. Já as operações de pesca efetuadas por embarcações pequenas apresentaram um custo operacional médio de $\mathrm{R} \$ 700,00$ por expedição de pesca. Os combustíveis se destacam como principal responsável pelos custos totais em todas categorias (Figura 6).

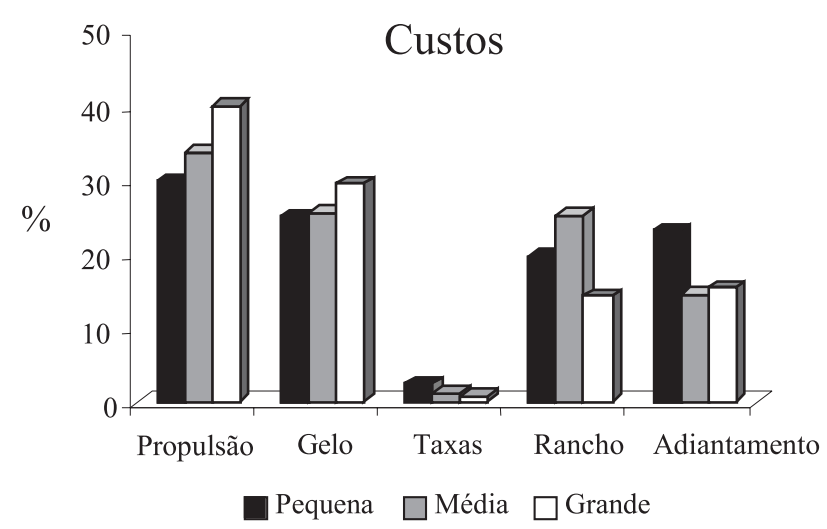

Figura 6 - Composição dos custos referentes às expedições de pesca para embarcações pequenas, médias e grandes.
Gasto com gelo, rancho e adiantamentos aos pescadores, compartilham quase similarmente os demais custos variáveis associados diretamente às expedições de pesca (Figura 6). Entretanto, há diferenças no peso de cada componente de custo, sendo gelo o segundo mais importante, particularmente para grandes embarcações. A operação das embarcações pequenas gera despesas com rancho e adiantamentos para os pescadores, comparativamente elevadas, embora suas viagens de pesca sejam curtas e os pescadores não apresentem funções especializadas. O peso dos adiantamentos para a saída das expedições de pesca das embarcações médias é similar às observadas para embarcações grandes, havendo porém forte peso dos custos com rancho.

Para as embarcações pequenas, o custo operacional médio representou cerca de $45,2 \%$ da renda bruta auferida com a venda do pescado enquanto que o custo para as embarcações médias e grandes representou $42,0 \%$ e $47,8 \%$ respectivamente.

A curva projetada para os dados de comprimento do barco e custo operacional médio coletado é apresentada na Figura 7, onde se verifica que a taxa de crescimento dos custos operacionais em média é maior e mais variável a medida em que aumenta o porte das embarcações, formando uma nuvem de pontos observados que se ajustam a um modelo exponencial.

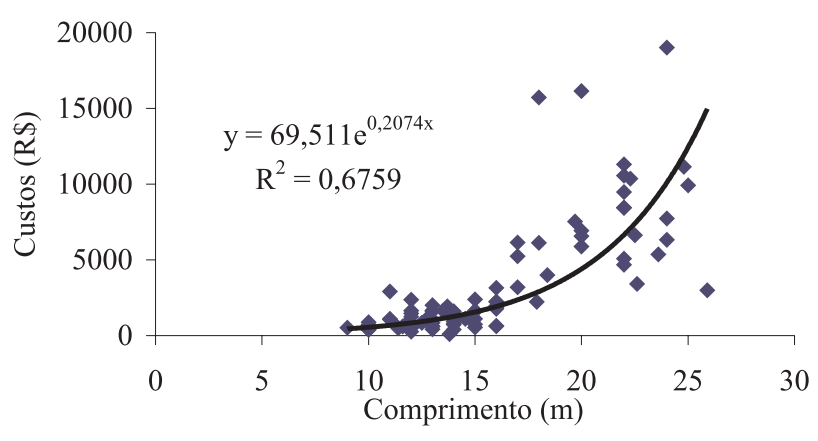

Figura 7 - Relação do custo operacional por expedição de pesca com o comprimento da embarcação, com indicação do modelo ajustado e equação obtida.

\section{Rentabilidade da expedição de pesca}

A renda bruta auferida com a venda do pescado para as embarcações, bem como a remuneração dos pescadores são mostradas nas Tabelas 1 e 2, respectivamente. Para embarcações pequenas, que efetuam mais expedições de pesca por mês ( 3 expedições em média), a remuneração dos pescadores correspondeu a 1,1 salário mínimo mensal ( $\mathrm{R} \$ 151,00$ na época). Para embarcações médias, a remuneração dos pescadores (excluindo-se o encarregado) variou conforme a função entre 0,67 a 2,13 e nas grandes embarcações, variou entre 1,20 a 2,25 salários mínimos. 


\section{ACTA AMAZONICA}

Tabela 1 - Custo e renda média das embarcações amostradas.

\begin{tabular}{|c|c|c|c|c|c|c|c|}
\hline Embarcação & $\begin{array}{l}\text { Renda Bruta } \\
\text { Média (R\$) }\end{array}$ & $\begin{array}{l}\text { Despachante } \\
(\mathrm{R} \$)^{1}\end{array}$ & $\begin{array}{l}\text { Custo Médio } \\
\text { Expedição }(R \$)^{2}\end{array}$ & $\begin{array}{l}\text { Renda } 1^{3} \\
(\mathrm{R} \$)\end{array}$ & $\begin{array}{l}\text { Renda } 2^{4} \\
\text { (R\$) }\end{array}$ & $\begin{array}{c}\text { Barco }^{5} \\
\text { (R\$) }\end{array}$ & $\begin{array}{l}\text { Pescador }^{6} \\
\text { (R\$) }\end{array}$ \\
\hline Pequena & $1.297,00$ & 129,00 & 587,00 & $1.168,00$ & 580,00 & 290,00 & 58,00 \\
\hline Média & $4.452,00$ & 445,00 & $1.870,00$ & $4.007,00$ & $2.137,00$ & $1.068,00$ & * \\
\hline Grande & $17.661,00$ & $1.766,00$ & $8.400,00$ & $15.895,00$ & $7.494,00$ & $3.747,00$ & * \\
\hline
\end{tabular}

$1-10 \%$ sobre a renda bruta apurada; 2 - Custo efetivo = despesas com expedição menos o valor adiantado (deduzido da renda dos pescadores); 3 - Renda 1 $=$ renda bruta menos a porcentagem do despachante; 4 - Renda $2=$ Renda 1 menos o valor do custo da expedição; $5-50 \%$ da Renda 2; 6 - Parte da Renda 2 correspondente às cotas dos pescadores (embarcações de pequeno porte); * - Tabela 2.

Tabela 2 - Remuneração do armador e pescadores das embarcações por expedição de pesca.

\begin{tabular}{lccccccccc}
\hline \hline & \multicolumn{2}{c}{ Embarcações pequenas } & \multicolumn{2}{c}{ Embarcações médias } & \multicolumn{2}{c}{ Embarcações grandes } \\
\cline { 2 - 10 } & Cotas & R $\$$ & SM $^{1}$ & Cotas & R $\$$ & SM $^{1}$ & Cotas & R\$ & SM $^{1}$ \\
\hline Renda média & & 580,00 & & & $2.137,00$ & & & $7.494,00$ \\
Armador & $50 \%$ & 290,00 & + & $50 \%$ & $1.068,00$ & 7,08 & $50 \%$ & $3.747,00$ & 24,82 \\
Encarregado & - & - & - & 5,7 & 322,00 & 2,13 & 8,8 & 934,00 & 6,19 \\
Motorista & - & - & - & 2,6 & 147,00 & 0,97 & 3,2 & 339,00 & 2,25 \\
Cozinheiro & - & - & - & 1,9 & 107,00 & 0,71 & 2,0 & 212,00 & 1,41 \\
Largador & - & - & - & 2,4 & 135,00 & 0,90 & 2,3 & 244,00 & 1,62 \\
$2^{\circ}$ lanceiro & - & - & - & 2,1 & 118,00 & 0,79 & 2,0 & 212,00 & 1,41 \\
Gelador & - & - & - & 2,4 & 135,00 & 0,90 & 2,5 & 266,00 & 1,76 \\
Descolador & - & - & - & - & - & - & 2,0 & 212,00 & 1,41 \\
Cambiteiro & - & - & - & 1,8 & 101,00 & 0,67 & 1,7 & 180,00 & 1,20 \\
Ajudantes & - & - & - & - & - & - & $1,8(\times 6)$ & 191,00 & 1,27 \\
\hline \hline
\end{tabular}

1 - SM : Salário Mínimo em 20.07.2000, R\$ 151,00; + - Tabela 1.

\section{DISCUSSÃO}

O maior aporte de desembarques efetuados pela frota interiorana na capital do Estado do Amazonas comparativamente ao da frota baseada na cidade de Manaus (mais de dois terços do desembarque total), indica que o mercado da capital é considerado mais conveniente e lucrativo que o do interior, o que foi confirmado por depoimentos dos próprios pescadores. Nos municípios de origem, o pescado não tem mercado suficiente para absorver toda a produção, ou o preço de venda do pescado nestes municípios é muito baixo e não compensatório. Esses dados estão de acordo com Parente (1996) que detectou essa contribuição como sendo de $70,6 \%$.

A origem do pescado capturado também é descentralizada, conforme indicaram Petrere Jr. (1978; 1982; 1983) e Batista (1998), embora o percentual declarado no presente estudo, para viagens aos pesqueiros do rio Purus esteja aumentando sua importância como região de pesca para o abastecimento de Manaus (Batista, 1998; Soares \& Junk, 2000). Pertencente à calha do rio Solimões, a região de Coari apareceu com destaque como contribuinte desse sistema para Manaus, sendo que tanto o rio Purus quanto o rio Solimões até este município deveriam ser prioritários nos estudos bio-ecológicos e de avaliação de impactos das ações antrópicas sobre os recursos pesqueiros.

O número de pescadores é elevado devido à grande quantidade de embarcações de pesca e indica que o pescado possui uma importante função social para manutenção de empregos (Almeida et al., 2000; 2001), comparativamente ao que ocorre na pesca industrial estuarina e marinha do litoral norte, que emprega poucos pescadores (IBAMA, 1997). Por outro lado, essa quantidade elevada de pescadores deve conduzir à redução da renda per capta em comparação com sistemas de pesca mais intensivos e de maior poder de pesca que os utilizados na região de estudo, o que é típico em pescarias de pequena escala (Berkes et al., 2001). Destaca-se ainda que o emprego gerado tem base predominantemente rural (Almeida et al., 2001).

A dependência do setor em relação à pesca, aqui indicada pelo elevado percentual de armadores que têm na pesca sua única atividade e fonte de renda, é muito grande. Diversos trabalhadores do setor declararam com freqüência que a pesca era seu único ofício, sendo uma evidência de que o sistema é pouco elástico para suportar 


\section{ACTA \\ AMAZONICA}

ASPECTOS ECONÔMICOS E OPERACIONAIS DAS VIAGENS

DA FROTA PESQUEIRA DE MANAUS, AMAZÔNIA CENTRAL escassez de pescado ou restrições na explotação pesqueira, o que poderia reduzir a oferta e elevar o valor do produto. Esta inflexibilidade de mão-de-obra é comum no setor pesqueiro (Parente, 1996), devendo ser estudada a priori para permitir a melhor alocação deste, de modo que viabilize a melhora da economicidade do setor.

A predominância da tramalha (malhadeira multifilamento) nas pequenas embarcações não deve ser interpretada como preferência, visto que os proprietários destas usualmente não têm capital para a aquisição e manutenção de apetrechos mais onerosos, como são as redinhas (Bittencourt \& Cox-Fernandes, 1990), havendo uma tendência de migração para estas quando se capitalizam o suficiente. As embarcações de médio porte apresentaram uma tendência a utilizarem maior diversidade de apetrechos de pesca, isso pode ter influenciado na maior diversidade de pescado que foi declarado como sendo usualmente desembarcado por embarcações desse porte.

Os dados referentes à forma de propulsão utilizado nas embarcações diferem do informado por Falabella (1994), que sugeriu uma proporção igual entre os motores YANMAR e MWM para a frota existente até maio de 1983. Na atualidade, a proporção dos motores YANMAR aumentou em relação aos motores MWM e outros, compatibilizando os resultados com o obtido por Batista (1998) que, comentou a predominância de motores YANMAR por serem confiáveis e pela facilidade na manutenção.

Os dados obtidos sobre os agentes financiadores da pesca estão de acordo com o obtido por Falabella (1994) e Parente (1996), destacando-se armadores, despachantes, frigoríficos, pontões, comerciantes (mercearias, supermercados) e os próprios pescadores como principais agentes. Não foi observada a inclusão do agente despachante para o financiamento das expedições de embarcações grandes, o que pode ser explicado pelo fato da maioria dos armadores dessa classe serem também despachantes (Parente, 1996).

A distribuição das embarcações de pesca em classes permitiu uma melhor visão dos custos de cada expedição de pesca, sendo estes extremamente diferenciados em relação ao porte. Os resultados obtidos mostraram que ocorreu uma redução do custo com combustíveis, em relação aos resultados apresentados por Falabella (1994), essa redução pode derivar da modernização do maquinário e da boa conservação dos mesmos. Entretanto, quando se compara o gasto de combustível relacionado ao porte da embarcação, se verifica que o gasto é maior em embarcações grandes (Almeida et al., 2000), provavelmente devido à maior distância percorrida por essas embarcações (Petrere Jr., 1978; Batista, 1998) onerando assim as expedições, tanto no gasto com combustíveis quanto no consumo de rancho. O mesmo não foi verificado para as embarcações pequenas e médias, onde os combustíveis representam $30 \%$ e $34 \%$ desses custos.
$O$ ajuste do modelo exponencial indica que embarcações grandes podem ter um custo crescente, sendo viáveis apenas com pescarias de alto rendimento, sendo assim um fator limitante em sua expansão na região. Já embarcações de até 16 metros têm custos similares, sendo mais adequadas para a formação de micro-frotas sub-regionais.

Um ponto relevante na comercialização do pescado é que trazer o produto para a venda em Manaus não significa retorno dos custos envolvidos na expedição, pois o faturamento depende do mercado local (leilão), da oferta e demanda no momento da venda e da espécie de pescado, resultando em grandes flutuações no valor do produto.

A distribuição da remuneração dos pescadores está de acordo com o obtido por Parente (1996), onde o montante a receber é relacionado com a função que cada um pescador desempenha na equipe. Para embarcações médias e grandes o sistema adotado para remuneração dos pescadores é o de cotas-parte, diferindo apenas para embarcações pequenas, onde as partes são divididas similarmente entre a tripulação, muito embora o baixo número de embarcações pequenas amostradas restrinja a generalidade desta observação.

A remuneração do pescador pode ser dobrada ou adicionada de mais cotas, dependendo da "produtividade do pescador", ou do acúmulo de funções dentro da embarcação durante uma expedição de pesca. Observouse um aumento na remuneração dos pescadores das embarcações grandes, em relação aos valores encontrados por Parente (1996) para a mesma classe de embarcações, não diferindo os valores de remuneração para embarcações médias. A subdivisão em funções com remuneração diferenciada também foi observada para a região de Santarém (Baixo rio Amazonas) por Almeida et al. (2001), mas registrando apenas as categorias de proprietários e pescadores.

\section{CONCLUSÕES}

A análise efetuada dos dados coletados permitiu concluir que:

a) A dependência da atividade pesqueira para os armadores de pesca, atinge valores próximos a $54 \%$ o que caracteriza a importância do setor para essa classe;

b) O custo operacional médio por expedição de pesca varia entre 42 e $48 \%$ da renda bruta auferida com a venda do pescado, sendo que os combustíveis apresentaram uma diminuição na participação efetiva nos custos por expedição de pesca, quando comparado com o apresentado por Falabella (1994), para a década de 80 (custos > 50\% da renda bruta), porém, segue em destaque como principal componente desses custos;

c) Um modelo exponencial foi adequado para relacionar os valores de custo operacional médio e comprimento da embarcação; 


\section{ACTA AMAZONICA}

d) Houve um aumento na remuneração dos pescadores das embarcações grandes, quando comparados com os valores encontrados na literatura existente.

\section{AGRADECIMENTOS}

Os autores agradecem ao CNPq, pela concessão da bolsa de IC (processo 520111/97-4), IPAAM e BASA pelo apoio financeiro ao projeto. Aos técnicos do Laboratório de Avaliação e Manejo da Pesca, aos revisores pelas sugestóes e críticas e aos armadores e pescadores que com suas informações, tornaram possível este trabalho.

\section{BIBLIOGRAFIA CITADA}

Almeida, O.T.; McGrath, D.G.; Arima, E.; Ruffino, M.L. 2000. Production analysis of commercial fishing in the lower Amazon. In: The Eighth Conference of the International Association for the Study of Common Property, Constituting the commons: Crafting sustainable commons in the new millennium. Bloomington, Indiana, USA. May 31 - June 04. Disponível em: http://dlc.dlib.indiana.edu

Almeida, O.T.; McGrath, D.G.; Ruffino, M.L. 2001. The commercial fisheries of the lower Amazon: an economic analysis. Fisheries Management and Ecology, 8:253-269.

Batista, V.S. 1998. Distribuição, dinâmica da frota e dos recursos pesqueiros na Amazônia Central. Tese de Doutorado, Instituto Nacional de Pesquisas da Amazônia/Fundação Universidade Federal do Amazonas, Manaus, Amazonas. 282p.

Berkes, F.; Mahon, R.; McConney, P.; Pollnac, R.; Pomeroy, R. 2001. Managing small-scale fisheries: Alternative directions and methods. International Development Center Research - IDCR, Canada. 320p.

Bittencourt, M.M.; Cox-Fernandes, C. 1990. Peixes migradores sustentam pesca comercial. Ciência Hoje, 11(64): 20-24.

Falabella, P.G.R. 1994. A pesca no Amazonas: problemas e soluções. $2^{\text {a }}$ edição. Manaus: Imprensa Oficial do Estado, 180p.
FAO. 1997. Inland fisheries. FAO Technical Guidelines for Responsible Fisheries. Rome. No. 6. 36p.

FAO. 1999. Review of the state of world fishery resources: inland fisheries. FAO Fisheries Circular, Rome. No. 942. 53p.

IBAMA. 1997. Relatório da V reunião do grupo permanente de estudos - GPE. Piramutaba. Belém, 26-29.08.97. IBAMA, (mimeo).

Merona, B.; Bittencourt, M.M. 1988. A pesca na Amazônia através dos desembarques no mercado de Manaus: resultados preliminares. Memória Sociedad Ciencias Naturales La Salle, 48(Suplemento 2): 433-453.

Parente, V.M. 1996. A economia da pesca em Manaus: Organização da produção e da comercialização. Dissertação de Mestrado, Universidade Federal Rural do Rio de Janeiro, Rio de Janeiro. 178p.

Petrere Jr., M. 1978. Pesca e esforço de pesca no Estado do Amazonas. II. Locais e aparelhos de captura e estatística de desembarque. Acta Amazonica. 8(Suplemento 2): 1-54.

Petrere Jr., M. 1982. Ecology of the fisheries in the River Amazon and tributaries in the Amazonas state (Brazil). PhD Thesis, University of East Anglia, UK. 96p.

Petrere Jr., M. 1983. Yield per recruit of the tambaqui, Colossoma macropomum Cuvier, in Amazonas State, Brazil.J. Fish Biol., 22: $133-144$

Soares, M.G.M.; Junk, W.J. 2000. Commercial fishery and fish culture of the state of Amazonas: Status and perspectives. In: Junk, W.J.; Ohly, J.J.; Piedade, M.T.F.; Soares, M.G.M. (eds.). The Central Amazon Floodplain: Actual Use and Options for a Sustainable Management. Backhuys Publishers, Netherlands. p. 433-461. 
